\title{
ASYMPTOIMATIC TRANSIENT SA-NODE CONDUCTION BLOCK IN A PATIENT WITH ACUTE RISPERIDONE+TRIHEXYPHENYDYL TABLET POISONING
}

KEY WORDS:

Dr Varun Kumar M C*

\section{Dr Shyojiram}

Meena

Dr Dhiresh Salvi

\section{Dr Pramod}

\section{Chaurasiya}

Junior Resident $\left(3^{\text {rd }}\right)$; Department Of Medicine; GMC Kota. *Corresponding Author

Senior Professor \& Unit Head; Department Of Medicine; Gmc Kota.

Junior Resident $\left(2^{\text {nd }}\right)$;Department Of Medicine; GMC Kota.

Assistant Professor; Department Of Medicine; GMC Kota.

BACKGROUND: a case report of 17 year old male with acute risperidone + trihexyphenidyl poisoning with transient sinoatrial block without any CNS or neuromuscular complications.

CONCLUSION: Risperidone does possess cardiotoxicity as of cardiac conduction abnormalities mainly affecting SA and AV nodes rather than prolongation of QT interval without causing hypotension or myocardial injury ${ }^{1}$. Such a nonlethal conduction aberrancy was observed at a dose of $75 \mathrm{mg}$ risperidone was only transient and reversed physiologically without any additional treatment. Further protection from extrapyramidal symptoms was offered by combined drug trihexyphenidyl at cost of sedation.

A 17year old male brought to medicine emergency after 30 minutes of alleged history of consumption of 25 tablets of RISPIRIDONE+TRIHEXYPHENYDYL $(3 \mathrm{mg} / 2 \mathrm{mg})$ with a suicidal intent, upon history patient had no other symptoms except feeling of excessive sleepiness, patient had no past history of any psychiatric illness or nor any medical complications such as Hypertension, diabetes mellitus, heart disease or cerebro-vascular accident and no significant family history. Patient was an occasional alcoholic with 2 pints of beer in month which caused no addiction as informed by attenders.

Upon general physical examination patient was conscious, drowsy, well oriented to time place and person. His vitals pulse rate 82 beats per minute regular with no radio-radial or radio-femoral delay, respiratory rate 16 cycles/min, blood pressure $110 / 70 \mathrm{mmHg}$ supine in right upper limb. Systemic examination cardiovascular, respiratory, per-abdomen and Central-nervous system were within normal limits. An initial Ecg was taken before admission which was within normal limits (fig-1)

(FIG-1).

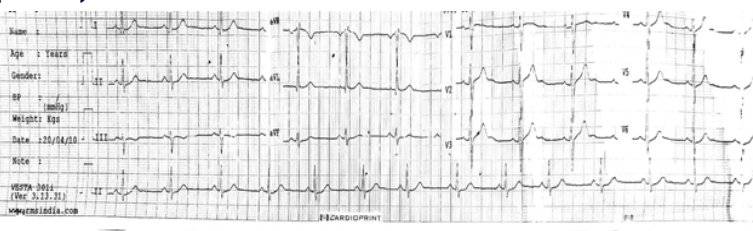

Patient was admitted kept under observation, initially managed with gastric lavage with normal saline and iv fluids of about 1 liter (GNS 5\%), and other symptomatic management, 3-hours post admission patient went into state of deep sleep responding with grimace and abnormal flexion response on deep pain stimulation, his pupils were 3-4 mm reacting to light with bilateral absent plantar reflexes, no dystonic reactions on further examination It was noted that patient had an irregular pulse with a rate of around 50 beats per minute with no apex-base deficit cardiac examination revealed intermittent skipped beats with normal sounds and no murmur patient had normal respiration with brief interval of apnea lasting for about 30-40 seconds with no fall in saturation and blood pressure $110 / 80 \mathrm{mmHg}$. Patient was put on prone positioning to secure airway kept nil by mouth and attached with vital monitor which recorded pulse rate of 40BPM and $98 \%$ saturation on room air.

www.worldwidejournals.com
Ecg was taken which showed SA-nodal block type 2 with junctional escape with grouping of $\mathrm{P}$ - QRS complexes and there was no QT prolongation or ST-T changes (FIG-2)

\section{(FIG-2)}

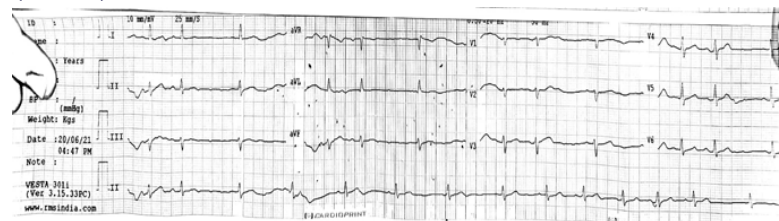

Patient was then connected to continuous cardiac monitor which read same ECG for next 6 hours before patient regained consciousness 10 hours post admission with no confusion or other CNS abnormalities or neuromuscular complications. Investigations for cardiac abnormality were repeated at intervals of 12 hours since admission and were within normal limits as shown below in

TABLENO 1.

\begin{tabular}{|c|c|c|c|}
\hline TEST & BASELINE & 12-HOURS & 24- HOURS \\
\hline $\begin{array}{l}\text { TROP-I } \\
(0-0.4 \mathrm{ng} / \mathrm{l})\end{array}$ & & $0.21 \mathrm{ng} / \mathrm{l}$ & \\
\hline $\begin{array}{l}\text { TROP-T } \\
\text { (Card test) }\end{array}$ & ---------------------- & NEGATIVE & \\
\hline $\begin{array}{l}\text { CK-MB } \\
\text { (Up to 25IU/1) }\end{array}$ & $10 \mathrm{IU} / 1$ & $20 \mathrm{IU} / 1$ & $16 \mathrm{IU} / \mathrm{L}$ \\
\hline $\begin{array}{l}\mathrm{LDH} \\
(240-480 \mathrm{IU} / 1)\end{array}$ & $106 \mathrm{IU} / 1$ & $150 \mathrm{IU} / 1$ & $216 \mathrm{IU} / 1$ \\
\hline
\end{tabular}

A third Ecg recorded 24 hours post admission was within normal limits except for sinus bradycardia (FIG-3).

(FIG-3)

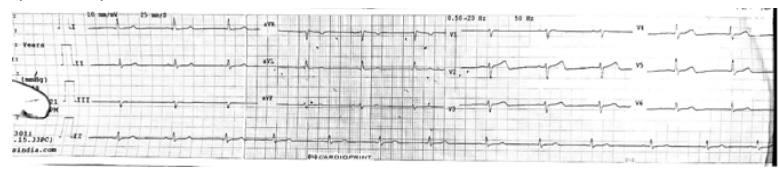

Patient was comfortable and had no symptoms such as dizziness, syncope, palpitations or confusion, further patient was kept under observation for next 5 days which was uneventful. Patient was discharged after reassurance and thorough psychiatrist and cardiology reference. follow-up done after 1 week showed no additional symptoms nor any dynamic changes in ECG 


\section{CONCLUSION}

Acute atypical anti-psychotic (risperidone) poisoning either accidental or suicidal intention is a frequent problem presenting to emergency department. therapeutic effects are best observed with a dose of max $6 \mathrm{mg}$ in both adults and children, above which adverse effects start to appear. It has to be noted from the above case report that only cardiac arrythmia has resulted from risperidone due to effective control of extrapyramidal symptoms was by trihexyphenidyl (THP), further such cardiac arrythmia needed no further evaluation if the effect is only transient and caused no QT prolongation, hypotension or underlying myocardial injury can be managed symptomatically under observation. Although studies conducted in this regard have made a note on CNS toxicity such as extrapyramidal effects developing anywhere between 1 week to 2 years, reversible neuromuscular and cardiac abnormalities ${ }^{1 .}$, particular data on type of cardiac abnormalities occurring in the same has not been mentioned. Besides some studies have also been reported to have no cardiotoxic effects of risperidone ${ }^{2}$ hereby stands inconclusive. Adding on studies have also mentioned incidence of increased incidence of sudden cardiac death in atypical antidepressant users due to increased incidence of cardiac arrythmias from potassium channel blockade and prolongation of cardiac repolarization ${ }^{3}$ cannot be neglected if arrythmia is prolonged or if there is severe bradycardia. This case report is to add volumes on understudied cardiac arrythmias by Risperidone.

\section{REFERENCES}

1) Allison A Acri, Fred M Henretig, Effects of risperidone in overdose, The American Journal of Emergency Medicine, Volume 16, Issue 5,1998, Pages 498-501, ISSN 0735-6757, https://doi.org/10.1016/S0735-6757(98)900018.(https://www.sciencedirect.com/science/article/pii/S0735675798900018)

2) Page CB, Calver LA, Isbister GK. Risperidone overdose causes extrapyramidal effects but not cardiac toxicity.J Clin Psychopharmacol. 2010 Aug;30(4):387-90. doi: 10.1097/JCP.0b013e3181 e5f7a5.PMID:20631557.

3) Laroussinie G, Zenut M, Béal M, Bernard C, Lavarenne J. Intoxication aiguë par la rispéridone et perturbations ioniques et électrocardiographiques [Acute poisoning by risperidone and ionic and electrocardiographic changes]. Therapie. 1997 Mar-Apr;52(2):155-6.French.PMID:9231512. 